\title{
The Use2Use Design Toolkit-Tools for User-Centred Circular Design
}

\author{
Oskar Rexfelt ${ }^{1, *(\mathbb{D}}$ and Anneli Selvefors ${ }^{2}$ \\ 1 Department of Industrial and Materials Science, Chalmers University of Technology, \\ 41296 Gothenburg, Sweden \\ 2 Forming Futures, 41323 Gothenburg, Sweden; anneli@formingfutures.se \\ * Correspondence: rex@chalmers.se
}

Citation: Rexfelt, O.; Selvefors, A. The Use2Use Design Toolkit-Tools for User-Centred Circular Design. Sustainability 2021, 13, 5397. https:// doi.org/10.3390/su13105397

Academic Editor: Grigorios

L. Kyriakopoulos

Received: 31 March 2021

Accepted: 8 May 2021

Published: 12 May 2021

Publisher's Note: MDPI stays neutral with regard to jurisdictional claims in published maps and institutional affiliations.

Copyright: (c) 2021 by the authors. Licensee MDPI, Basel, Switzerland. This article is an open access article distributed under the terms and conditions of the Creative Commons Attribution (CC BY) license (https:// creativecommons.org/licenses/by/ $4.0 /)$.

\begin{abstract}
Recent research highlights that the important role users play in the transition to a circular economy is often overlooked. While the current narrative emphasises how to design products fit for circular (re-)production flows, or how to design circular business models, it often fails to address how such solutions can be designed to be attractive to people. As long as products and services are designed in a way that makes people prefer linear options over circular ones, the transition will not gain momentum. To further the understanding of how a user perspective can be valuable for circular design, this paper introduces the Use2Use Design Toolkit and presents initial experiences from using its five tools in design work. The tools were developed between 2016 and 2019 and subsequently applied in 30 workshops with professionals and students. Insights from the workshops suggest that the participants generally found the tools fun, instructive and inspirational. The tools enabled them to discuss circular processes from a user's point of view and to identify challenges and design opportunities. The toolkit was considered especially relevant and meaningful by product and service designers who needed support to explore circular solutions from a user perspective.
\end{abstract}

Keywords: circular design; user-centred design; sustainable design; design tools; circular economy; circular consumption

\section{Introduction}

The circular economy has been promoted as a potential enabler for sustainable development [1-3]. The key objective of the circular economy is to optimise the use of produced objects and materials [4]. This can be achieved by enabling long-term product use and circular product flows that allow for repair, redistribution, refurbishment or remanufacturing when needed in between uses. Only when products have become obsolete, should material and parts be circulated and recycled [4]. Designing products and services that enable tight product loops without excessive (re-)production is especially important, since it may increase the utilization of produced products and the potential for circulating under-utilised products to new users at their highest utility and value. Moreover, tight loops have the potential to be more profitable and resource-efficient, since resource-intensive processes associated with (re-)production and material processing can be avoided $[1,4,5]$.

In recent years, many products and services have been developed and offered to consumers to enable and facilitate tight loops. Unfortunately, they often have limited success in replacing linear options and a large-scale circular transition is still far away. Apart from economic, structural, and political barriers, companies also experience barriers related to consumer demand and adoption [6,7]. As long as people prefer linear options over circular ones, the transition to a circular economy will not gain momentum.

Despite a growing need to address why people do not find circular offers more attractive, there is not enough emphasis on the important roles that consumers and consumption play in the transition to a circular economy [8-10]. The prevalent discourse is coloured by circular economy definitions that are often based on a simplified understanding of 
consumption (if present at all) [11]. It also points to opportunities for companies to design offers fit for circular production and business to a higher extent than circular consumption $[6,9]$. Although these opportunities are important, their framing increases the risk that design opportunities related to users and their consumption processes are overlooked.

\subsection{Viewing Circularity from a User Perspective}

Focusing only on opportunities for production and business, without considering issues of consumption, may limit the potential for new innovations to become attractive to people [12] and commercially profitable [9]. If we do not understand users, it is difficult to design business models that people aspire to [13]. Considering the role of consumers in the circular economy should not only be about addressing consumers' attitudes towards, and acceptance of, particular business models. A profound understanding of consumption, and what implications a shift from linear to circular consumption may entail for people's everyday lives, is needed to develop successful circular products and services.

Viewing circularity from such a user perspective makes it relevant to reframe consumers as users that have agency, and to acknowledge them as central enablers of circular product flows (cf. [14]). Their actions and decisions will not only determine whether pre-used products are obtained, but also whether products are passed on to new users once need for them has ceased [4]. This, in turn, points to the importance of companies enabling users to circulate products, and not the other way around. When exploring circular design opportunities from a user perspective, it becomes essential to shift focus from enabling companies' production processes to enabling people's consumption processes.

A consumption process can, in its most basic form, be divided into the three main phases: obtainment, use, and clearance (regarding wording: the literature often refers to these phases using other terms. In this paper, the terms obtainment and clearance have been chosen since they describe the acts in a neutral way but not the means by which they are done). Historically, obtainment and reasons why people purchase certain goods or services have received a lot of research attention, not least in marketing research [15]. In relation to circularity, understanding the entire consumption process is, however, central since people's actions in all phases can disrupt circular product flows. During recent years, several valuable contributions have helped to nuance the understanding of people's consumption processes in the context of the circular economy (see, e.g., $[16,17])$.

As illustrated in Figure 1, people can shift from being traditional consumers that engage in linear consumption processes (i.e., buying new products, using, and disposing of them as trash) to becoming users that engage in circular consumption processes (e.g., obtaining pre-used products, using, and clearing them by passing them on to others). Such circular paths of consumption require a transfer of product ownership or access from one user to another, i.e., that the product is transferred from use to use. The exchange of a particular product could be accomplished directly between users without any intermediary or be enabled by companies.

While a shift from linear to circular consumption may or may not influence which types of products people consume, it will certainly influence how people consume [12] Looking closer at the phases of obtainment, use, and clearance, they can be understood as sub-processes in which people make decisions and engage in a variety of activities. Circular paths of consumption may entail specific strings of activities and decisions, as well as certain everyday challenges and practicalities, which may make them less desirable than linear ones. At the risk of having to engage in cumbersome, time-consuming and undesirable activities, people might avoid circular consumption paths (e.g., selling used items on the second-hand market) and choose more convenient linear options (e.g., disposing of items as trash or storing them in the garage) [18]. 


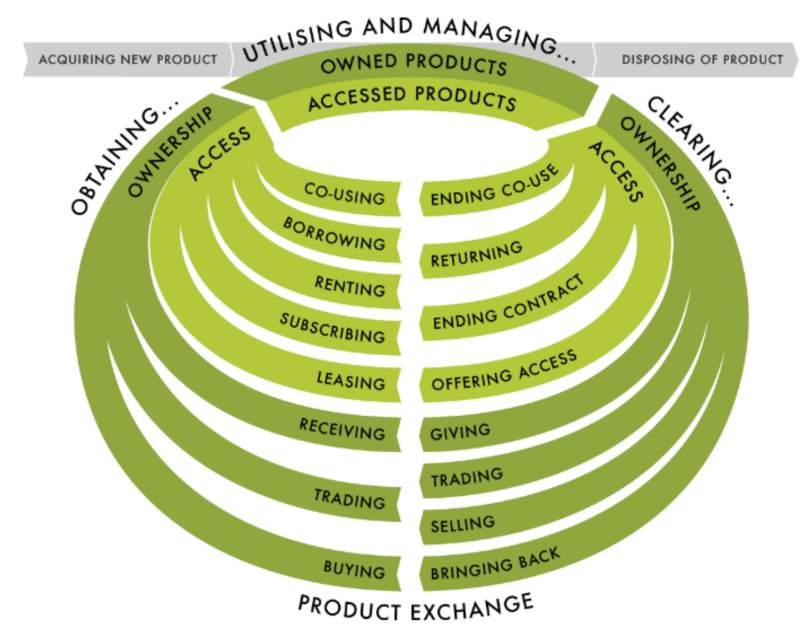

Figure 1. Examples of circular paths of consumption (adapted from [12]).

\subsection{User-Centred Circular Design Opportunities}

Designing for circular consumption (e.g., designing to make it easy and attractive to people to rent a product or buy it second hand) presents new types of challenges for designers [12]. Apart from enabling long-term use, designers must also consider how to make products fit for use by a sequence of users throughout multiple use-cycles and how to facilitate product exchange processes. For instance, designing for easy inspection, handling, and assessment becomes important, as does designing for diverse user needs, detachment, and long product careers. Gaining insight into such user-centred circular design opportunities is key to developing products and services that enable circular consumption and make it preferable to people.

Yet, most circular design methods and tools do not emphasise user-centred circular design opportunities. Instead, the majority of available tools (e.g., [19-21]) focus on circular business opportunities or opportunities to design products fit for circular (re-)production flows (see [22] for a review of such tools). Although tools of this kind often highlight that an understanding of the target customer can help assess market demand and acceptance for a particular circular offer, they do not to any higher degree acknowledge the need to gain user insight to inform design.

In contrast, the few circular design tools that do take a more user-centred approach highlight that user insight should be considered a valuable point of departure for design. For instance, the Circular Design Guide provided IDEO and Ellen MacArthur Foundation stresses the importance of conducting user-centred research as part of the design process [23]. However, the guide does not specify how user-centred research could be adapted to specifically gain insight into circular consumption processes.

In a review [24] exploring five circular design tools ([23,25-28]), it was concluded that although some of the reviewed tools acknowledge the need to gain insight about users and consumption, the tools do not address such aspects in sufficient detail. Another conclusion was that, in addition to factors of acceptance and conditions for adoption, circular design tools should focus more on the link between circular offerings and people's behaviours in all stages of the consumption process [24].

\subsection{Aim}

This paper aims to further the understanding of how a user perspective can be valuable for circular design by introducing a kit with user-centred circular design tools. The toolkit is developed to aid designers to specifically address design challenges and opportunities related to people's consumption processes. In addition, this paper will present initial experiences from using the tools in design work to discuss the toolkit's potential. 


\subsection{Paper Structure}

The paper initially covers a description of materials and methods used for developing the toolkit and for applying the tools in design work. The toolkit is subsequently described followed by a summary of how people experience the tools. More general implications regarding the toolkit's overall potential to support circular design are highlighted in the discussion along with recommendations for future work. A concluding section highlights key takeaways.

\section{Materials and Methods}

This paper reports results from two research projects carried out at Chalmers University of Technology. The first project concerned the development of the toolkit and the second project is currently carried out to apply the toolkit and evaluate its potential. The materials and methods used in each project are described below.

\subsection{Research Project 1: Development of the Use2Use Design Toolkit}

The toolkit presented in this paper is the result of an explorative and iterative process that began in 2013. The process was initiated with a workshop in which seven researchers in the fields of user-centred design and sustainable design explored how product circularity could be framed with the user taking centre stage. Already existing and common representations of product circularity were examined in order to obtain an understanding of how users were represented in these, and to explore potential new representations. A user perspective on circularity was developed during the following years (see [12,29] for a more detailed description).

In 2016, the work to embody this user perspective into a design toolkit was initiated. First, potentially valuable tool components, covering, e.g., need elicitation and ideation support, were developed. These early versions of the tools, as well as their subsequent iterations, were used to explore what would be valuable to designers and other agents. They were evaluated through three main research activities between 2016 and 2019. First, workshops were conducted during 2016 and 2017 with designers, product developers and product managers from six companies (in total four workshops, each with 6-8 company representatives) to verify the need for user-centred circular design tools and to identify important requirements. The workshops were arranged in collaboration with the companies Transformator Design and Hultafors Group. The participants were asked to explore circular consumption design opportunities related to their product and service offers aided by the early versions of the tools. The generated ideas and the participants' experiences of using the tools were discussed afterwards, both by the participants and the workshop organisers, and also analysed by the research team.

Second, refined versions of the tools were tested in workshops with design students in courses on sustainable design at Chalmers University of Technology (on six occasions altogether between 2017 and 2019, each with circa 30 students). The students' tasks were to gain an understanding of what circular consumption entail for people and come up with innovative ideas to make circular consumption preferable. The generated ideas and the tools' potential to support idea generation were discussed afterwards.

Third, refined versions of the tools were also applied by design students in their master thesis projects (in total by 13 students in seven teams) to identify design opportunities and suggest design concepts. The thesis projects concerned the design of a mobile application for sharing, a digital platform for sharing assets within the culture sector, an autonomous delivery droid for collaborative consumption, a tent for a rental service, a sofa for a furniture subscription service, earphones for a rental service, and cars for a sharing service. The experiences of the thesis students were observed throughout their projects and all students were interviewed retrospectively to gain insight into their use of the tools and the challenges they had experienced.

Through these activities, insights regarding the tools' potential value and usability were gained from both academia and industry, and opportunities to improve the tools 
were identified. The tools were adjusted and packaged into the Use2Use Design Toolkit consisting of five tools. The toolkit was officially released in 2020.

\subsection{Research Project 2: Applying the Toolkit in Design Work}

The tools' potential to support the development of products and services for circular consumption is currently being explored through different types of activities. One of the tools, the Use2Use Thinking Activation Pack, is mainly educational and was therefore applied in the form of lectures to inspire and spark discussion. The remaining four tools, which are meant to aid design work, were applied in workshops to explore user needs, identify design challenges, and ideate and evaluate design ideas.

Both professionals and students joined the lectures and workshops. The participants had varying competencies and roles, such as designers, project managers, and technical specialists. The professionals represented either consultancies or manufacturing companies, and the students partook in courses on sustainable design and circular economy at Chalmers University of Technology. Table 1 gives an overview of the number of participants that, so far, have been engaged by the authors in lectures and workshops utilizing the tools.

Table 1. Number of professionals and students that partook in lectures and workshops, as well as the total number of working groups for the workshops.

\begin{tabular}{|c|c|c|c|c|c|}
\hline & $\begin{array}{c}\text { Use2Use } \\
\text { Thinking } \\
\text { Activation Pack }\end{array}$ & $\begin{array}{l}\text { Circular Journeys } \\
\text { Exploration Pack }\end{array}$ & $\begin{array}{c}\text { Multiple } \\
\text { Use-Cycles } \\
\text { Exploration Pack }\end{array}$ & $\begin{array}{l}\text { Circular Designs } \\
\text { Ideation Pack }\end{array}$ & $\begin{array}{l}\text { Circular Designs } \\
\text { Evaluation Pack }\end{array}$ \\
\hline Professionals & $>400$ & 61 & 43 & 136 & 19 \\
\hline Occasions & 20 & 6 & 4 & 8 & 2 \\
\hline Working groups & (lecture only) & 14 & 11 & 31 & 5 \\
\hline Students & $>300$ & 70 & 70 & 210 & - \\
\hline Occasions & 7 & 2 & 2 & 6 & - \\
\hline Working groups & (lecture only) & 21 & 21 & 56 & - \\
\hline
\end{tabular}

For each workshop, the authors initially introduced the tool as well as a case to work on. The participants either applied the tools to purely fictious cases, or to cases resembling the companies' regular projects. Each workshop was ended with a follow-up discussion on gained insights, ideas, and the participants' impressions of the tool used. The original plan to conduct all workshops physically was adjusted due to the COVID-19 pandemic, and some workshops were instead organised online using digital workshop canvases. All workshops were first and foremost educational, but were also carried out to generate insights and ideas valuable to the participants. Due to the educational format, potential users of circular products and services have not been engaged in the workshops so far.

To gain insight into the potential of the four tools applied in workshops, three qualities central to design tools were explored: their usability, e.g., that they are easy and pleasant to use; their effectiveness in helping their users achieve the indented output; and their relevance to designers' everyday work. As shown in Figure 2, data regarding the tools' potential were collected and analysed in several ways. Qualitative data were collected through observations during the workshops and through the follow-up discussions after the workshops. The focus was on understanding the participants' experiences of using the tools, both regarding their usability and effectiveness, and whether the participants considered the tools relevant for their everyday work. Some of the workshops were conducted with committed project partner organisations that allowed for additional data collection. For these workshops, short follow-up surveys were also conducted prior to the follow-up discussions to complement the qualitative data. The surveys included seven Likert scale questions and the possibility to leave free-text comments. The focus for the surveys was also on collecting data related to the participants' experiences and the tools' 
relevance. Since one of the tools, the Use2Use Thinking Activation Pack, was applied in the form of lectures, no data were collected for this tool.

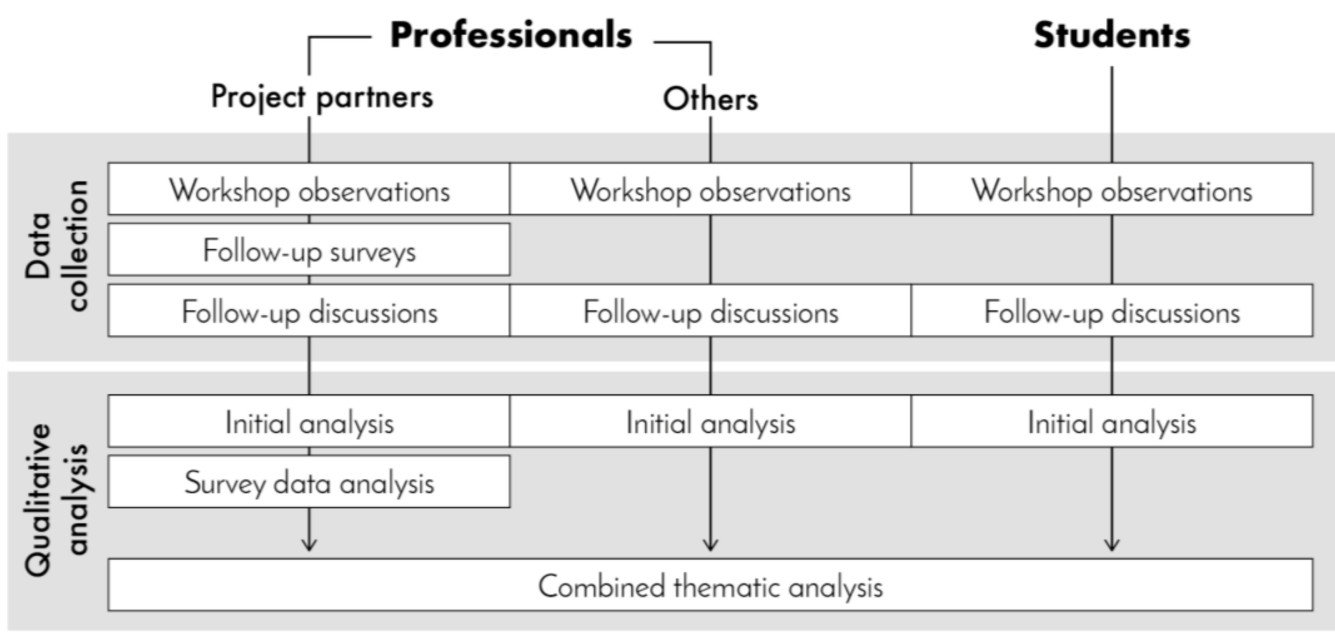

Figure 2. Overview of the workshop data collection and qualitative analysis for the three subsets of participants.

The collected insights were primarily analysed qualitatively to better understand how the tools may be of value. The analysis was conducted in relation to three overarching themes; the tools' usage, effectiveness, and relevance were explored to assess their potential. As illustrated in Figure 2, the analysis was done in three stages. First, an initial analysis was conducted after each workshop to gain insight into how each tool was perceived by the participants engaged in the different workshops. Second, the survey data from the project partner workshops were compiled and analysed for each tool. Third, insights from both the initial analyses and the survey analysis were examined in a combined thematic analysis. During the combined analysis, sub-themes related to the three overarching themes were explored, both for each tool and the whole toolkit. Representative quotes from the participants were selected to illustrate key insights and highlight both benefits and drawbacks.

\section{Results}

The Use2Use Design Toolkit is founded on two concepts: (1) a user perspective on circularity, and (2) user-centred design. The user perspective described in Section 1.1 highlights several important preconditions for circular design, such as viewing consumers as active users that may enable circular product flows, and that products and services should make circularity preferable to people in their everyday life. The user perspective is summarised in Table 2 and compared with how circularity commonly is described in the current discourse (see also [12] for a more in-depth comparison).

Table 2. Central aspects of the user perspective that the toolkit is based upon, in comparison with the prevalent discourse on circularity.

\begin{tabular}{cc}
\hline A user Perspective on Circularity & Prevalent Discourse on Circularity \\
\hline People viewed as the nexus of circularity & Companies viewed as the nexus of circularity \\
\hline $\begin{array}{c}\text { Circular flows described in relation } \\
\text { to people's consumption processes }\end{array}$ & $\begin{array}{c}\text { Circular flows described in relation } \\
\text { to the product life-cycle }\end{array}$ \\
\hline $\begin{array}{c}\text { Consumers viewed as active users } \\
\text { contributing to circular product flows }\end{array}$ & $\begin{array}{c}\text { Consumers viewed as passive } \\
\text { receivers of circular offers }\end{array}$ \\
\hline $\begin{array}{c}\text { Companies viewed as providers of products } \\
\text { and services that enable circular consumption }\end{array}$ & $\begin{array}{c}\text { Companies viewed as providers of products } \\
\text { and services fit for circular (re-)production }\end{array}$ \\
\hline
\end{tabular}


The second concept constituting the basis of the toolkit is user-centred design (UCD). It is a broad term to describe design processes in which users influence how a design takes shape, and in which the user is put centre-stage throughout the design process (see, e.g., [30]). This does not mean that any design process which in some way includes users will qualify as user-centred. The focal point is that the design of a product or service should be based on an understanding of the users, their needs, priorities, and experiences. There is no agreed-upon process for UCD, although a number of key activities are generally included in UCD process descriptions. In their simplest forms, these activities can be described as exploration, ideation and evaluation. Exploration is where one tries to understand the users and their contexts in order to identify their needs and requirements, which in turn informs the creative work. The output of the ideation activities, such as ideas and concepts, are then evaluated. The process is thereafter often iterative, where creative and evaluative efforts are alternated while the design is being continuously refined. User involvement in different ways is advocated in all three types of activities.

The tools in the Use2Use Design Toolkit are designed to be useful during the key activities of UCD. Much focus has been on developing tools to support the explorative work and help designers empathise with users, as this is the key driver for coming up with ideas for how to improve people's everyday life. The toolkit does not, however, come with a prescribed design process. Since design processes often need to be carried out differently depending on the case at hand, the tools were designed to be flexible and applicable in different processes.

\subsection{The Use2Use Design Toolkit}

The toolkit includes five tools designed to aid the development of products and services fit for circular consumption processes (see Figure 3). It is a toolkit focused on aiding designers and others to explore circular design opportunities from a user perspective. The toolkit is designed to highlight how design can enable and make it preferable for people to circulate products from user to user-that is, from use-to-use.

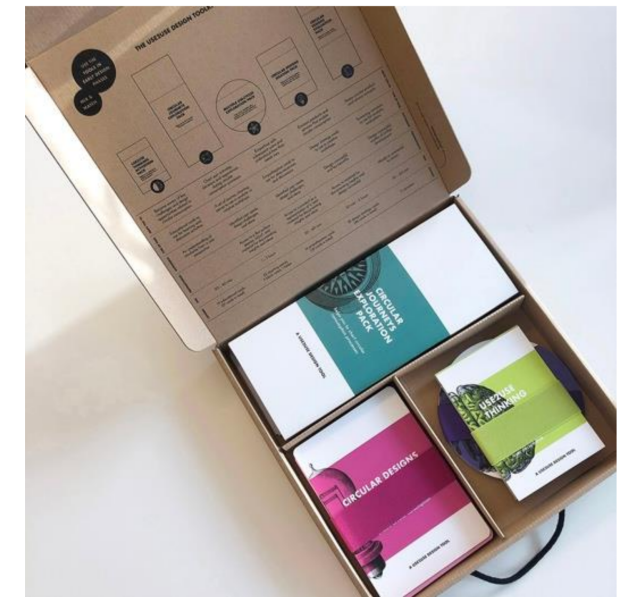

(a)

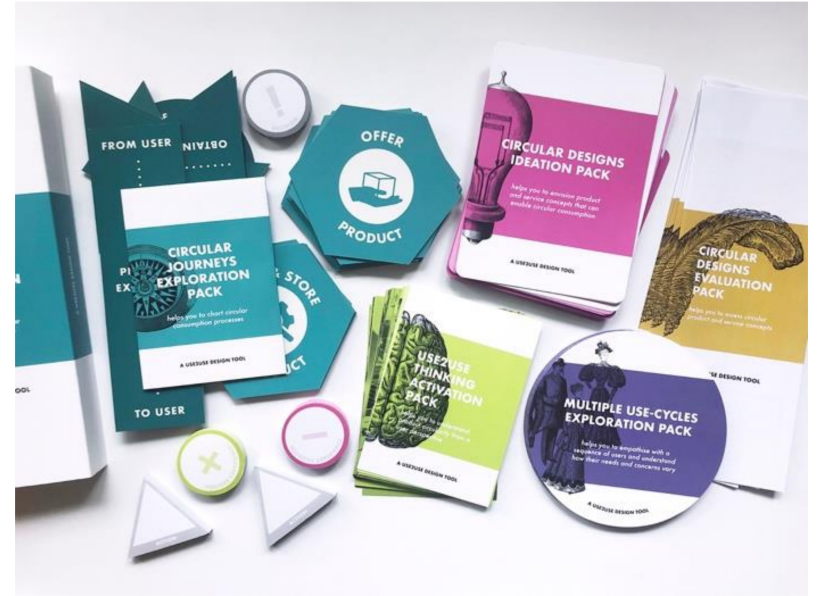

(b)

Figure 3. The Use2Use Design Toolkit: (a) the full kit with (b) the five tools included in the toolkit.

The tools are best used in early design phases to provide inspiration and structure during exploratory and creative sessions. The primary focus is on aiding the design of products and services, rather than aiding strategic decisions. The tools can help designers and others to elicit user needs, identify design challenges, create ideas and concepts, and evaluate concepts. They can be used consecutively but also independently of each other.

As illustrated in Table 3, the five tools differ regarding their purpose, type, expected outcome(s), and time required. The tools and their intended use are presented in more 
detail in Sections 3.1.1-3.1.5. The tools are further described and are freely available at www.use2use.se (accessed on 10 May 2021).

Table 3. Overview of the five tools and their key characteristics.

\begin{tabular}{|c|c|c|c|c|c|}
\hline & $\begin{array}{c}\text { Use2Use } \\
\text { Thinking } \\
\text { Activation Pack }\end{array}$ & $\begin{array}{l}\text { Circular Journeys } \\
\text { Exploration Pack }\end{array}$ & $\begin{array}{c}\text { Multiple } \\
\text { Use-Cycles } \\
\text { Exploration Pack }\end{array}$ & $\begin{array}{l}\text { Circular Designs } \\
\text { Ideation Pack }\end{array}$ & $\begin{array}{l}\text { Circular Designs } \\
\text { Evaluation Pack }\end{array}$ \\
\hline Purpose & $\begin{array}{l}\text { To help designers } \\
\text { and others to } \\
\text { understand the } \\
\text { benefits of } \\
\text { addressing } \\
\text { circularity from a } \\
\text { user perspective }\end{array}$ & $\begin{array}{l}\text { To help designers } \\
\text { and others to chart } \\
\text { circular } \\
\text { consumption } \\
\text { processes to } \\
\text { identify design } \\
\text { opportunities }\end{array}$ & $\begin{array}{l}\text { To help designers } \\
\text { and others to } \\
\text { empathise with a } \\
\text { sequence of users } \\
\text { and understand } \\
\text { how their needs } \\
\text { and concerns vary }\end{array}$ & $\begin{array}{l}\text { To help designers } \\
\text { and others to } \\
\text { envision product } \\
\text { and service } \\
\text { concepts that can } \\
\text { enable circular } \\
\text { consumption }\end{array}$ & $\begin{array}{l}\text { To help designers } \\
\text { and others to } \\
\text { assess circular } \\
\text { product and } \\
\text { service concepts }\end{array}$ \\
\hline Type of tool & $\begin{array}{c}\text { Educational cards } \\
\text { that support } \\
\text { learning and } \\
\text { discussion } \\
\text { activities }\end{array}$ & $\begin{array}{l}\text { A set of journey } \\
\text { charting pieces } \\
\text { that support } \\
\text { analytic or creative } \\
\text { workshops }\end{array}$ & $\begin{array}{l}\text { Empathy cards } \\
\text { that support relay } \\
\text { exercises and } \\
\text { discussions }\end{array}$ & $\begin{array}{c}\text { Design strategy } \\
\text { cards that support } \\
\text { creative } \\
\text { workshops }\end{array}$ & $\begin{array}{c}\text { Screening canvases } \\
\text { that support } \\
\text { analytic } \\
\text { evaluations }\end{array}$ \\
\hline $\begin{array}{c}\text { Expected } \\
\text { outcome(s) }\end{array}$ & $\begin{array}{l}\text { An understanding } \\
\text { of circularity from } \\
\text { a user perspective }\end{array}$ & $\begin{array}{l}\text { Identified user } \\
\text { needs, design } \\
\text { challenges, and } \\
\text { potential ideas }\end{array}$ & $\begin{array}{l}\text { Identified user } \\
\text { needs, design } \\
\text { challenges, and } \\
\text { potential ideas }\end{array}$ & $\begin{array}{l}\text { Design ideas or } \\
\text { concept(s) }\end{array}$ & $\begin{array}{l}\text { Design concept(s) } \\
\text { identified to be } \\
\text { worthy of further } \\
\text { development }\end{array}$ \\
\hline $\begin{array}{l}\text { Time typically } \\
\text { required }\end{array}$ & $20-60 \mathrm{~min}$ & $1-3 \mathrm{~h}$ & $30-60 \mathrm{~min}$ & $30 \mathrm{~min}-2 \mathrm{~h}$ & $30-60 \mathrm{~min}$ \\
\hline
\end{tabular}

\subsubsection{Use2Use Thinking Activation Pack}

The Use2Use Thinking Activation Pack provides an introduction to understanding, addressing and supporting circularity from a user perspective. It can aid designers and others to increase their understanding of why and how to design for circular consumption.

The tool is primarily educational and is designed to facilitate learning and stimulate discussion. As can be seen in Figure 4, the tool consists of a set of 19 educational cards, each underlining an important aspect related to the role users play in circularity. All cards have a statement on the front to spark curiosity, e.g., "Obsolescence is in the eye of the user" and "People don't care about business models". The topic of each quote is elaborated upon on the back of the cards. The cards can be used in any way people find them useful, e.g., for solitary reading and learning, for triggering discussions during seminars, or as inspiration during lunch breaks.

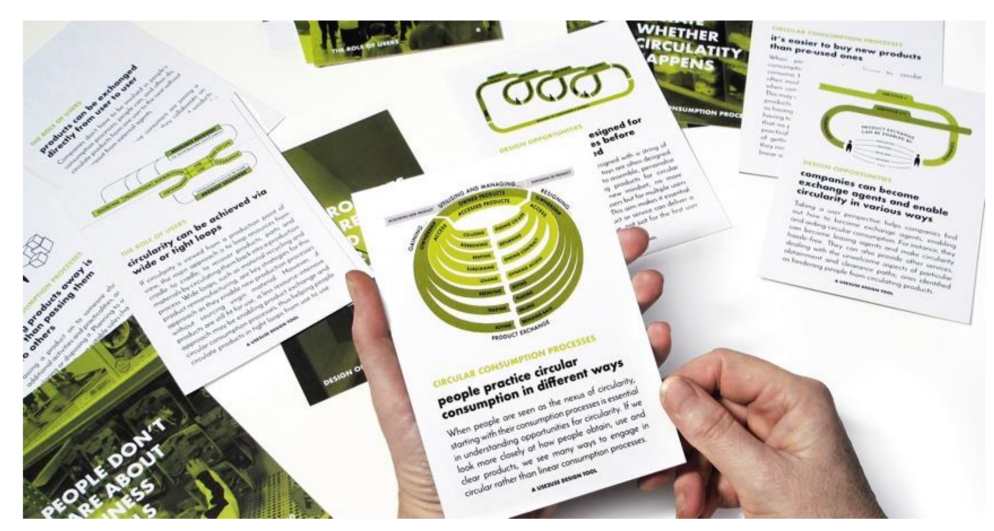

Figure 4. The Use2Use Thinking Activation Pack consists of a set of cards that can be used for learning and to stimulate discussion. 


\subsubsection{Circular Journeys Exploration Pack}

The Circular Journeys Exploration Pack supports designers and others to increase their understanding of how consumption processes are carried out and how people experience such processes (see [31] for a detailed description). The tool enables charting of people's consumption processes step-by-step so that critical hindrances to circularity can be unveiled and addressed later on.

The tool can be useful for a number of different design activities in the early exploratory stages of a design process. The tool can be used to chart consumption processes that have already been thoroughly researched through user studies, but this is, however, not a prerequisite for using the tool. Less explored journeys can also be charted, based on, for instance, one's own experience or assumptions. Furthermore, the tool can be used to mediate user studies to gain novel insights from consumers, to ideate and prototype potential future consumption processes, and to compare and evaluate different journeys.

As shown in Figure 5, the tool consists of a set of pieces that facilitate the charting of people's consumption processes. The most central pieces are the hexagonal activity pieces, which constitute the backbone of every charted consumption journey. These pieces are pre-defined and describe the main consumption activities, such as "Explore obtainment opportunities", "Initiate product use", and "Prepare product for clearance". The set of activity pieces covers key activities that may be relevant to consider in relation to the three main phases of a consumption process: obtainment, use, and clearance. The pack also contains pieces that can be used to describe how these activities are carried out and pieces to highlight important decisions and experiences. Describing actions, decisions and experiences is key to identifying critical design challenges that must be addressed.

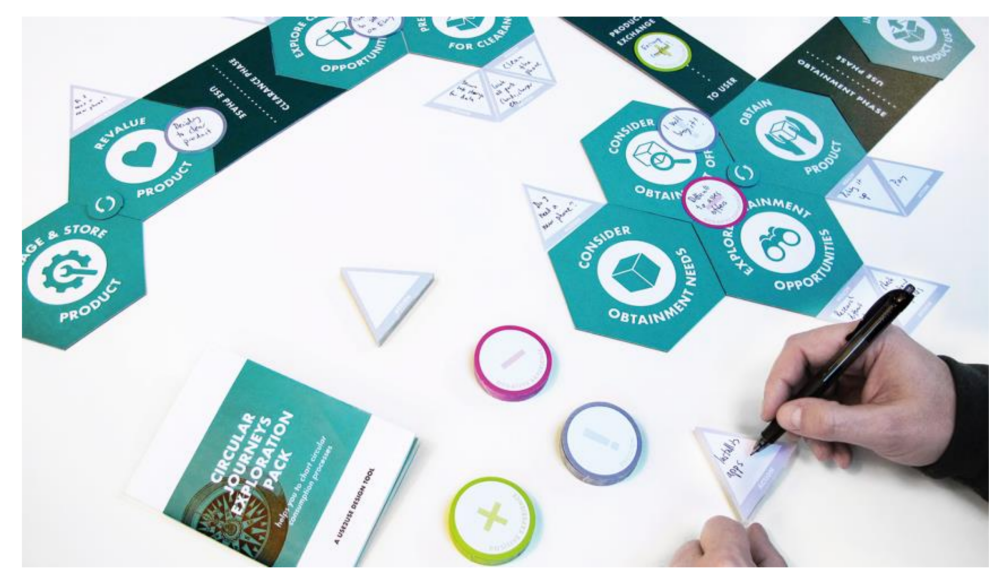

Figure 5. The Circular Journeys Exploration Pack can be used to chart consumption processes to identify design opportunities.

The tool can be used to chart a single user's entire consumption process (i.e., from obtainment to use and clearance) as well as particularly interesting segments of the process. In some cases, it may be meaningful to chart just the clearance phase. As illustrated in Figure 6, the tool can also be used to chart the process of two subsequent users. If charting "renting a car", it might be relevant to chart the whole process for a single user, but if charting "selling a mobile phone", it could be more meaningful to chart both the seller's process and how it links to the buyer's process. 


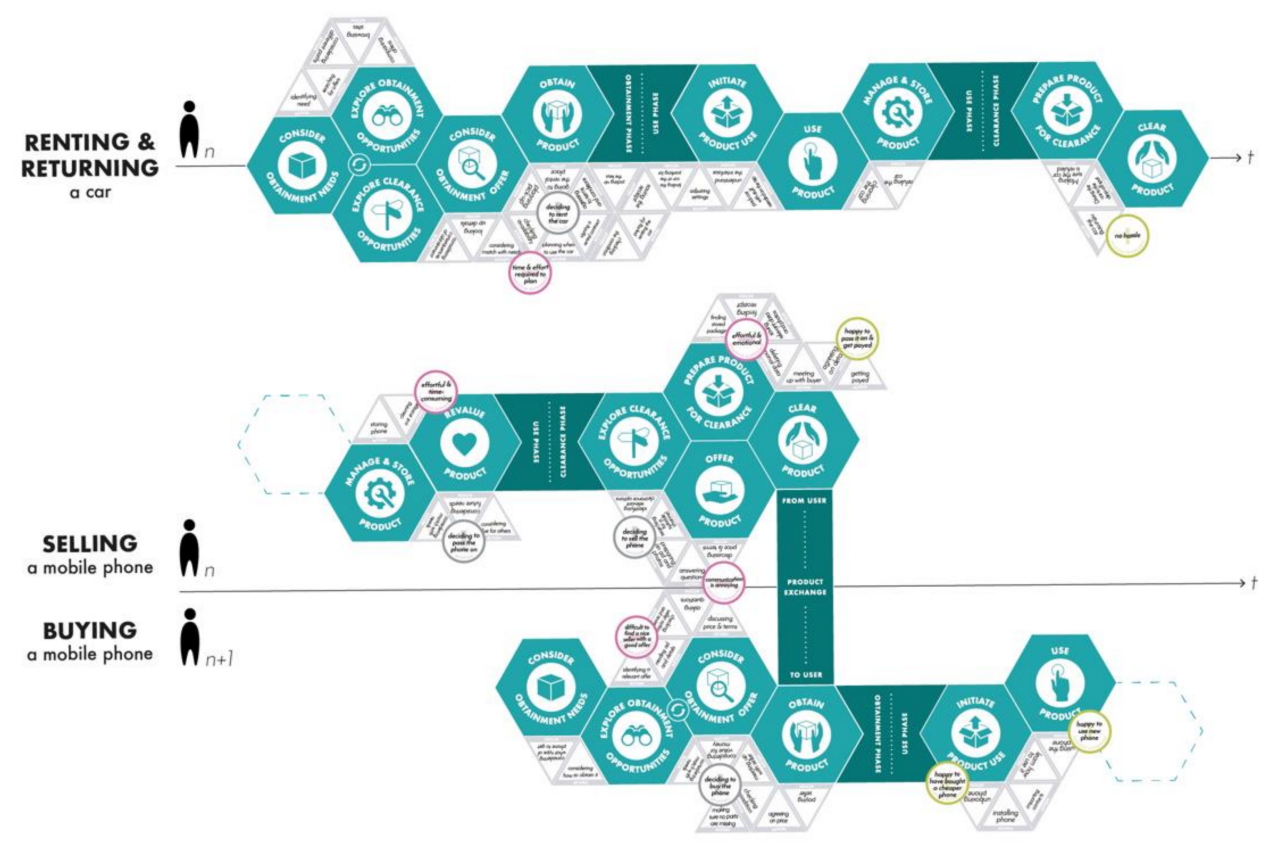

Figure 6. The tool can be used to chart a variety of journeys.

If journeys are charted based on previously conducted in-depth user studies or as part of conducting new user studies, the expected result can be a rather detailed and realistic description of the journey. This may be advantageous in many cases, as it can unveil more design challenges compared to less detailed journeys. Nevertheless, sometimes a less detailed journey is enough to identify the most critical design challenges to address.

\subsubsection{Multiple Use-Cycles Exploration Pack}

The Multiple Use-Cycles Exploration Pack helps designers and others to identify design challenges of particular relevance to products that will be circulated from user to user. The tool highlights needs, problems and concerns that sequences of users may experience throughout multiple use-cycles. It allows designers and others to empathise with users and understand how their needs vary.

The tool consists of a set of 14 empathy cards that underline important aspects to consider when aiming to design products for use by a sequence of users. As can be seen in Figure 7, every card highlights a quote, e.g., "I have just obtained the product from the previous user. I' $m$ worried that parts of the product or its accessories are missing". The quote is followed by a number of questions to trigger discussion regarding the topic of the quote, and to support the identification of related design challenges. Using the tool can, for instance, unveil how activities that are carried out often during circular consumption processes make it important to re-prioritise product requirements. If, say, a product is to be used by a new inexperienced user every day, it will become even more important for it to be intuitive to use.

The tool is designed to stimulate a relay session in which a group of people use the cards to explore needs and concerns and to identify important design challenges in relation to a particular product or product type. During such sessions, a product (or a depiction of it) is passed between the participants. Each time the product is handed over, the "new user" draws an empathy card, and the topic of the card is discussed in relation to the product. The tool can be used by designers and others involved in designing the product, but potential users can also be invited to participate. 


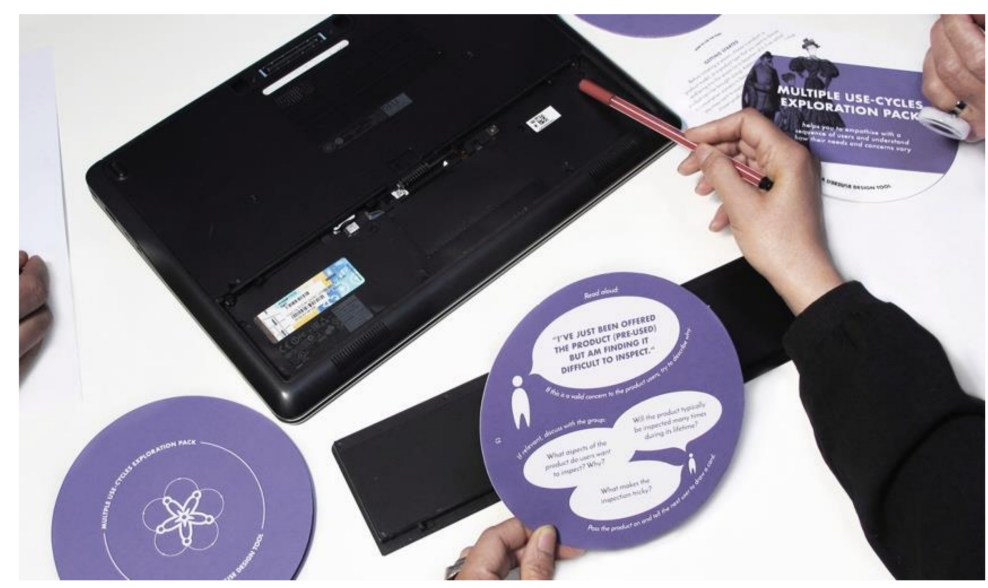

Figure 7. The Multiple Use-Cycles Exploration Pack can be used to empathise with sequences of users to identify key design challenges.

\subsubsection{Circular Designs Ideation Pack}

The Circular Designs Ideation Pack helps designers and others to envision products and services that enable circular consumption. The tool highlights a number of design opportunities to stimulate discussion, support ideation activities and spark new ideas.

The tool covers four main design strategies that can be considered when aiming to make circular consumption more attractive to people: Design for Extended Use, Design for Multiple Use-Cycles, Design for Exchange, and Design for Circular Match-Making. The strategies point to a variety of design opportunities and are, as illustrated in Figure 8, related to people's consumption processes in different ways. The strategy Design for Extended Use is related to the use phase and addresses challenges associated with a product's lowered utility, attractiveness, and need-fulfilment over time. The strategy Design for Multiple UseCycles addresses challenges that arise when products are repeatedly circulated from use to use. For instance, design challenges associated with diverse user needs, shortened usecycles, and long product histories are important to consider to make each use-cycle relevant and attractive to people. The strategy Design for Exchange highlights the importance of facilitating people's obtainment and clearance processes, i.e., facilitating the process of product exchange. For example, it highlights design opportunities for addressing practicalities associated with handling pre-used products before and after use, assessing pre-used products and circular offers, and re-activating products stuck in disuse limbo. The strategy Design for Circular Match-Making addresses design challenges related to interactions between two subsequent users. It covers challenges around how people can be supported to connect, trust, avoid conflicts, and make deals with others.

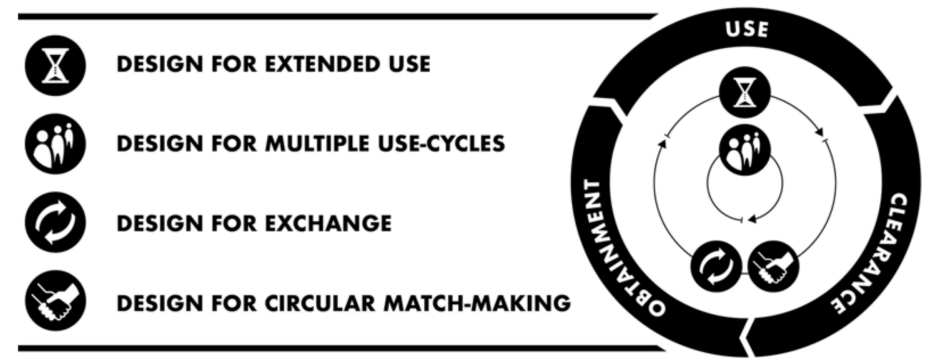

Figure 8. The tool highlights four main design strategies that address aspects related to different stages of the consumption process.

The tool consists of a deck of cards that includes an introduction to the four design strategies and 38 ideation cards that highlight design opportunities related to the strategies. As shown in Figure 9, each ideation card has a short introduction that describes which 
design challenge the card addresses. A main ideation question is highlighted followed by a set of trigger questions that exemplifies particular "hows". An inspiring design example, i.e., a product or service that can help users overcome the described challenge, is included on the back of each card. Although the ideation cards and examples may highlight opportunities for either product or service design, a particular design challenge can often be addressed by both.

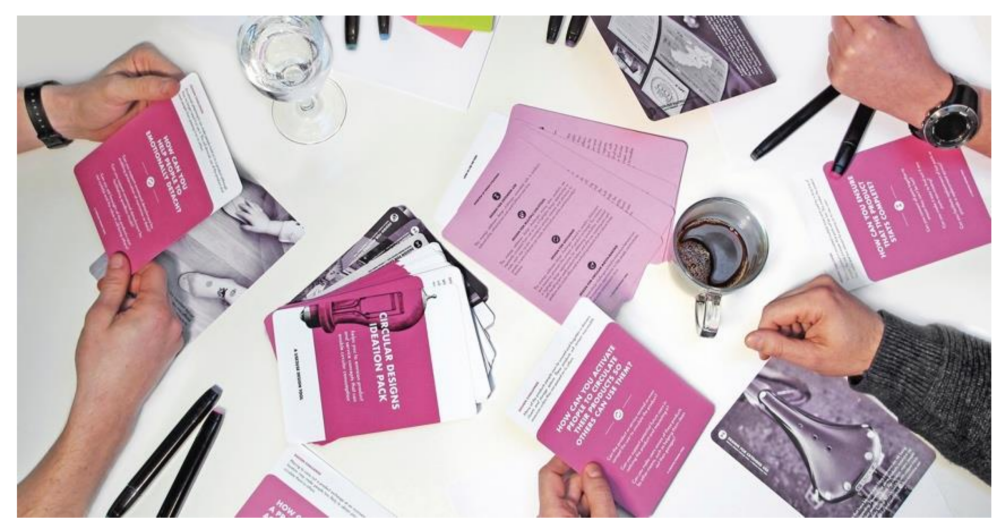

Figure 9. The Circular Designs Ideation Pack can be used to support ideation sessions and exploration of products and service concepts.

The tool can be used in ideation sessions to get acquainted with new design challenges or to address challenges previously identified. For each ideation session, one can either choose to focus on a few challenges based on previous insights or start off with all cards and later exclude irrelevant ones. All ideation cards, and the design challenges they address, will most likely not be relevant to consider in all cases. Using the Circular Journeys Exploration Pack and the Multiple Use-Cycles Exploration Pack beforehand is beneficial as they will provide insight into which design challenges are most relevant to focus on.

\subsubsection{Circular Designs Evaluation Pack}

The Circular Designs Evaluation Pack helps designers and others to assess circular concepts. It can be used to compare different products or to compare services offering access to products.

As shown in Figure 10, the tool consists of a canvas with a large evaluation matrix, in many ways similar to a Pugh-matrix [32]. Each concept is evaluated from the point of view of three different stakeholders: the users, the organisation (usually the company providing the product or service), and the environment. For each of the stakeholders, two aspects are evaluated. The first one is potential, referring to the effects the concept will have for the stakeholders if it is implemented. The other aspect is implementation, which refers to what is needed to successfully implement the concept.

To aid assessment of concepts from each stakeholder's point of view, supportive questions are included on the canvas. The canvas also has a section to mark all the concepts on a chart similar to a PICK-chart [33], often referred to as an impact-effort matrix. This way, all concepts can be compared regarding their potential effects, and how effortful the implementation process may be. 


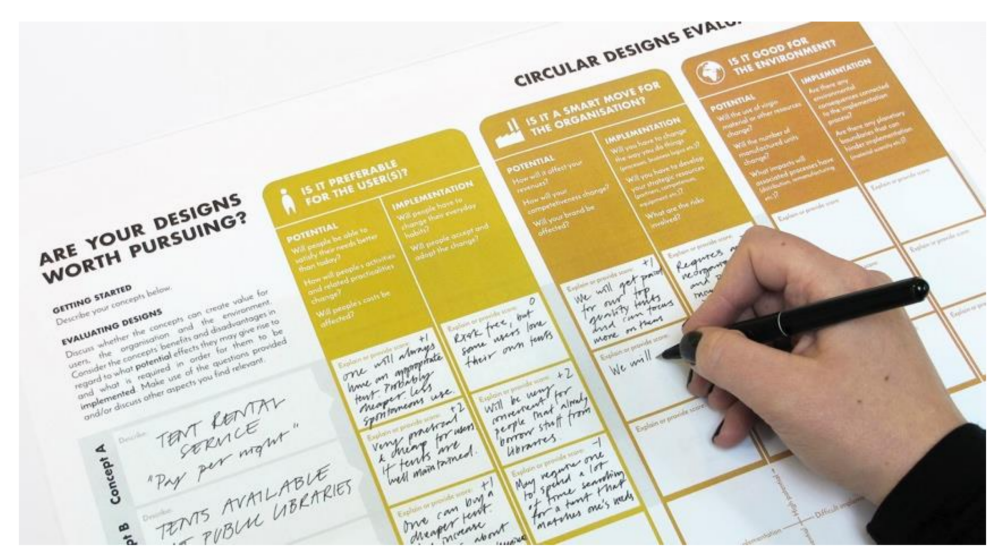

Figure 10. The Circular Designs Evaluation Pack can be used to assess design concepts.

\subsection{Experiences from Applying the Tools in Design Work}

The experiences gained when applying the tools in workshops will be described related to three main themes: the tools' usage, effectiveness, and relevance. Since the aim of this paper is to discuss the potential of the toolkit, and not to compare the individual tools with one another, the focus will be to describe overall experiences. More general implications regarding the toolkit's overall potential to support circular design will then be further explored in the discussion.

\subsubsection{Usage}

The participants that used the tools had positive experiences overall, and comments like "This is good stuff!", "Overall, this is great" and "What a fun tool" were common. As Table 4 shows, the survey data also support this, as the tools were ranked high on both Boring/Fun and Time-consuming and effortful/Quick and convenient. The participants commented on the tools' inviting design and appreciated the physicality of the format: "I like working together, physically. One can pick up two cards and compare them, read together, and point at them".

Many participants also commented that the toolkit was an easy way to get started with the complex topic of circularity: "I can participate without being a circular economy pro". It seems as though the user perspective integrated in the tools was an important enabler for this: "To focus on the user plays it all down somehow, you do not need to focus on business development to begin with" and "Starting in people's everyday is easy, challenging a company's business model is not". Overall, it was clear that both professionals and students, irrespective of their background, could easily use the tools. When observing the workshops, however, it appeared as though the participants with design experience got the hang of it all slightly quicker than the others.

There were, however, some aspects that the participants found challenging. When using the Circular Journeys Exploration Pack, the participants needed some time to get going due to the untraditional format of the tool. Many participants also commented on the number of cards in the Circular Designs Ideation Pack. Some said that the sheer number of cards made the tool more challenging to use; they found it to be difficult to gain an overview and identify the most relevant ones. Some also thought that it was a bit tricky to visually differentiate one card from another. Other participants viewed the number of cards as an advantage: "It felt luxurious to have all these cards prepared for me to choose from". 
Table 4. Overview of survey data collected from project partners regarding the tools' usage, usefulness, and applicability. The table shows both median values and min-max values in brackets.

\begin{tabular}{|c|c|c|c|c|}
\hline $\begin{array}{l}\text { Survey Questions } \\
\text { Likert Scales 1-7 }\end{array}$ & $\begin{array}{l}\text { Circular Journeys } \\
\text { Exploration Pack } \\
\quad(\mathbf{N}=26)\end{array}$ & $\begin{array}{l}\text { Multiple Use-Cycles } \\
\text { Exploration Pack } \\
(\mathbf{N}=30)\end{array}$ & $\begin{array}{l}\text { Circular Designs } \\
\text { Ideation Pack } \\
\quad(\mathbf{N}=44)\end{array}$ & $\begin{array}{l}\text { Circular Designs } \\
\text { Evaluation Pack } \\
\quad(\mathbf{N}=10)\end{array}$ \\
\hline \multicolumn{5}{|l|}{ Using the tool was: } \\
\hline 1: Boring-7: Fun & $6,5(5-7)$ & $6(4-7)$ & $6(4-7)$ & $5(4-6)$ \\
\hline $\begin{array}{l}\text { 1: Time-consuming and } \\
\text { effortful-7: Quick } \\
\text { and convenient }\end{array}$ & $6(4-7)$ & $6(5-7)$ & $5(2-7)$ & $5,5(4-7)$ \\
\hline 1: Uninstructive-7: Instructive & $6(4-7)$ & $6(5-7)$ & $6(3-7)$ & $5(4-6)$ \\
\hline 1: Uninspiring—7: Inspiring & $5(2-7)$ & $6(3-7)$ & $5(2-7)$ & $6(3-7)$ \\
\hline \multicolumn{5}{|l|}{ Using the tool resulted in: } \\
\hline $\begin{array}{c}\text { 1: Known insights and ideas-7: } \\
\text { New insights and ideas }\end{array}$ & $6(2-7)$ & $5(2-7)$ & $5(1-7)$ & $5(3-7)$ \\
\hline $\begin{array}{l}\text { 1: Insights and ideas with no } \\
\text { potential-7: Insights and ideas } \\
\text { with high potential }\end{array}$ & $6(4-7)$ & $5(2-7)$ & $5(2-7)$ & $5(3-7)$ \\
\hline \multicolumn{5}{|l|}{$\begin{array}{l}\text { Using the tool in my } \\
\text { everyday work would be: }\end{array}$} \\
\hline 1: Irrelevant-7: Rewarding & $5(1-7)$ & $5(1-7)$ & $5(1-7)$ & $5(2-7)$ \\
\hline 1: Difficult_7: Easy & $4(1-7)$ & $6(1-7)$ & $4,5(1-7)$ & $4,5(1-7)$ \\
\hline
\end{tabular}

\subsubsection{Effectiveness}

Overall, the participants found the tools effective in generating meaningful results. Many commented on how the tools helped them to view circularity from the user's point of view, and that they increased their understanding of the challenges circular consumption entails for people's everyday life. The tools were considered to be both instructive and inspirational, and the participants appreciated the tools' design with its many triggering questions: "It's incredibly valuable to be served all these thought-provoking questions for free", "This is perfect brainstorming material!". It is clear that the tools were effective in sparking discussions that the participants found valuable.

A few participants, in particular those who had used more than one of the tools in a sequence, were, however, slightly unsure of the novelty of insights and ideas generated during the workshops. Some of them felt that certain insights and ideas had already been covered when using the other tools beforehand, indicating an overlap in regard to the questions and topics addressed: "Sometimes we discussed similar ideas that had already been discussed in previous steps".

The tools' explorative format was appreciated since it inspired discussion, although some participants explained that it also made it difficult to decide on what level of detail to focus on: "When we worked on a general level it was easier to formulate cohesive concepts, but when we worked more in detail, we got deeper insights."

The workshops typically resulted in a mix of ideas related to products and services. The participants expressed that some product design ideas would be difficult to manage before one knew more about the solution on a service level. The nature of the ideas could also entail various consequences for future implementation: "Some of our ideas would mean that the company's operations would have to change drastically". When discussing more holistic concepts, it was easy to forget ideas dealing with details.

\subsubsection{Relevance}

The follow-up discussions, as well as the survey data in Table 4, point to the fact that the participants had varying opinions regarding whether it would be Rewarding/Irrelevant and Easy/Difficult to use the tools in their everyday work. This is connected to the mix of participants. Some did not currently have a position, or clients, that made it relevant to 
work with circular solutions: "The relevance is totally dependent on what project I'm working on. Right now, I am working for a local authority so ... but in other cases, absolutely!". In contrast, other participants had tasks where the tools would be a better match: "I already work with similar questions as I am the chief designer for a service exactly like the one in our workshop case. But I still found the tool [Circular Designs Ideation Pack] very useful!".

In general, participants with a user-centred design background found the toolkit spot on: "It enables user-centred designers to relate to and address circularity", "That's why it fits us so well, because that's how we think. We conduct user studies to understand more about the user, before we start working on solutions". Both students and professionals also considered the tools to be apt for cross-functional design work as it enabled people that do not normally work with product and service design to work together with more experienced designers. The possibility of inviting potential users of circular products and services to take part in workshops was also frequently mentioned as a potential benefit. Furthermore, participants working at design agencies highlighted that the tools would be useful in sessions together with their business clients: "It would really make them expand their minds and get new ideas".

\section{Discussion}

This section presents general insights and their implications followed by recommendations for future research.

\subsection{A User-Centred Perspective}

The workshop participants appreciated the tools' focus on users and consumption. They acknowledged the importance of understanding users' consumption processes, and that such an understanding can spark ideas for products and services fit for circular consumption. A general demand for the toolkit (observed through 1000+ downloads on www.use2use.se (accessed on 10 May 2021) during the first year following the release in March 2020) further indicates that the toolkit, with its user-centred perspective, is a welcome addition to the flora of circular design tools.

Nevertheless, while many workshop participants considered the user perspective relatable and a relatively easy way to approach circularity, a need to address other perspectives was also expressed. While the Circular Designs Evaluation Pack does support evaluation from a user, business, and environmental perspective, it is foremost a tool to help discuss and screen early ideas and concepts, and it is not particularly in-depth. The Use2Use Design Toolkit can thus be categorised as a niche toolkit with a one-eyed perspective. Such a niche toolkit might not be what all companies with an interest in the circular economy need the most, and it is certainly not the only thing they need. After having used the tools, many participants were unsure on how to proceed with their newly developed concepts and expressed a need for using other tools to further explore the concepts' potential from, for instance, a business or a sustainability perspective. Some companies were hesitant towards taking the risks they associate with circular ventures, and the one-eyed perspective was not sufficient to help them address these risks. It is therefore key to clearly understand what the toolkit is for, and what it is not for, before applying it.

\subsection{Integrating the Toolkit into Design Processes}

Since the main purpose of the workshops was educational, mainly focused on getting the participants acquainted with the tools and their use, the setting differed from the participants' ordinary contexts. Hence, the workshops lacked the normal aims, processes, documentation routines, etc., present in companies' regular processes. Some participants expressed that they needed guidance on what they were supposed to do when using the tools. "How are we supposed to document our insights?", "What kind of ideas are we supposed to generate?", "How do we take the next step?" and similar questions were quite common. Issues of this kind are primarily related to the format of the workshops, rather than the tools themselves. If the tools are to be applied in regular processes to address real cases, 
the experienced issues will likely be replaced by other challenges. Instead of struggling with an artificial setting, the key challenge will be to integrate the use of the tools into an already established structure with clear aims, gates, routines, etc. For instance, companies must decide on when to use which tool, who should use it, and whether any adjustments are required for a particular case.

\subsection{Future Research}

How to integrate the tools in company processes, where they can be used when needed and not be enforced in 'artificial' workshop settings needs to be further explored. The authors have already planned more longitudinal research activities to study how the tools can be integrated and utilised in existing processes in order to better support companies to design for circular consumption. When the tools are used in companies' regular processes, and not primarily for educational purposes, it also becomes possible to study how potential circular product and service users can contribute and partake in the design processes. In addition, it will be possible to assess resulting designs to evaluate the toolkit's potential to aid development of solutions that truly make circular solutions preferable to people.

Testing and assessment in other contexts and for a variety of products and services would also be valuable. Furthermore, exploring how the Use2Use Design Toolkit complements other circular design tools and how it can be used in combination with other tools is also needed.

To further the understanding of what a user perspective may entail for circular design, additional aspects not covered by the Use2Use Design Toolkit should also be explored. For instance, research is needed to explore in more detail how design can support people to appropriate and adopt circular solutions, and to explore how design can create pathways towards sufficiency.

\section{Conclusions}

This paper has introduced the Use2Use Design Toolkit to highlight ways to apply a user perspective in circular design. Initial experiences from applying the tools in design work point to that both novices and experienced user-centred designers and circular designers found the tools valuable. They expressed that the tools broadened their understanding of circularity and that they got hands-on support to explore new directions and ideas for making circular solutions preferable to people.

Author Contributions: Conceptualization, O.R. and A.S.; methodology, O.R. and A.S.; formal analysis, O.R. and A.S; investigation, O.R. and A.S; data curation, O.R. and A.S; writing O.R. and A.S.; funding acquisition, O.R. and A.S. Both authors have read and agreed to the published version of the manuscript.

Funding: Both research projects were funded by the Kamprad Family Foundation, grant numbers 20160136 and 20200190.

Institutional Review Board Statement: Not applicable.

Informed Consent Statement: Informed consent was obtained from all subjects involved in the study.

Data Availability Statement: Data can be requested from the corresponding author.

Acknowledgments: The toolkit presented in this paper has been developed by the authors. This would not have been possible without the valuable contributions of a number of people: Helena Strömberg and Sara Renström at Chalmers University of Technology; Stina Behrens, Kajsa Davidsson and Maria Bergström at the service design firm Transformator Design; and Daniel Ekfjorden with colleagues at Hultafors Group. The authors would also like to thank the students, professionals, and organisations that have taken part in trying out the tools and provided valuable feedback.

Conflicts of Interest: The authors declare no conflict of interest. The funders had no role in the design of the study; in the collection, analyses, or interpretation of data; in the writing of the manuscript, or in the decision to publish the results. 


\section{References}

1. Ellen MacArthur Foundation. Towards the Circular Economy-Opportunities for the Consumer Goods Sector. 2013. Available online: https:/ / www.ellenmacarthurfoundation.org/publications/towards-the-circular-economy-vol-2-opportunities-for-theconsumer-goods-sector (accessed on 5 April 2018).

2. European Commission. Towards a Circular Economy: A Zero Waste Programme for Europe, COM(2014) 398 Final/2; European Commission: Brussels, Belgium, 2014.

3. United Nations. Transforming our World: The 2030 Agenda for Sustainable Development, A/RES/70/1; United Nations Office: Geneva, Switzerland, 2016.

4. Stahel, W.R. The Circular Economy: A User's Guide; Routledge: New York, NY, USA, 2019.

5. Webster, K. The Circular Economy: A Wealth of Flows, 2nd ed.; Ellen MacArthur Foundation Publishing: Isle of Wight, UK, 2017.

6. Piscicelli, L.; Ludden, G.D.S. The potential of Design for Behaviour Change to foster the transition to a circular economy. In Proceedings of the DRS 2016 International Conference, Brighton, UK, 28-30 June 2016; Design Research Society: London, UK, 2016; pp. 1305-1321.

7. Tunn, V.S.C. Circular Business Models for Consumer Markets. Ph.D. Thesis, Delft University of Technology, Delft, The Netherlands, 6 October 2020. [CrossRef]

8. Camacho-Otero, J.; Boks, C.; Pettersen, I.N. Consumption in the Circular Economy: A Literature Review. Sustainability 2018, 10, 2758. [CrossRef]

9. Lofthouse, V.; Prendeville, S. Human-Centred Design of Products And Services for the Circular Economy-A Review. Des. J. 2018, 21, 451-476. [CrossRef]

10. Welch, D.; Keller, M.; Mandich, G. Imagined futures of everyday life in the circular economy. Interactions 2017, $24,46-51$. [CrossRef]

11. Kirchherr, J.; Reike, D.; Hekkert, M. Conceptualizing the circular economy: An analysis of 114 definitions. Resour. Conserv. Recycl. 2017, 127, 221-232. [CrossRef]

12. Selvefors, A.; Rexfelt, O.; Renström, S.; Strömberg, H. Use to use-A user perspective on product circularity. J. Clean. Prod. 2019, 223, 1014-1028. [CrossRef]

13. Lofthouse, V.; Prendeville, S. Considering the user in the circular economy. In Proceedings of the Product Lifetimes And The Environment 2017 Conference, Delft, The Netherlands, 8-10 November 2017; IOS Press: Delft, The Netherlands, 2017; pp. 213-216.

14. Gallaud, D.; Laperche, B. Circular Economy, Industrial Ecology and Short Supply Chain; John Wiley \& Sons: Hoboken, NJ, USA, 2016.

15. Antonides, G.; Van Raaij, W.F. Consumer Behaviour: A European Perspective; John Wiley \& Sons Ltd.: Chichester, UK, 1998.

16. Camacho-Otero, J. Redrawing the Circle: Integrating a Consumption Perspective into the Circular Economy. Ph.D. Thesis, Norweigian University of Science and Technology, Trondheim, Norway, 23 June 2020.

17. Poppelaars, F.A. Let It Go: Designing the Divestment of Mobile Phones in a Circular Economy from a User Perspective. Ph.D. Thesis, Delft University of Technology, Delft, The Netherlands, 8 October 2020. [CrossRef]

18. Rexfelt, O.; Hiort af Ornäs, V. Consumer acceptance of product-service systems: Designing for relative advantages and uncertainty reductions. J. Manuf. Tech. Manag. 2009, 20, 674-699. [CrossRef]

19. CIRCit Nord. CIRCit Nord Tools. 2020. Available online: https:/ / circitnord.com/tools (accessed on 26 April 2021).

20. Konietzko, J.; Bocken, N.; Hultink, E.J. A tool to analyze, ideate and develop circular innovation ecosystems. Sustainability 2020, 12, 417. [CrossRef]

21. PA Consulting. Circular Business Model Guide. 2020. Available online: https://www2.paconsulting.com/SustainabilityEMFBDG-2020-11_LP-download.html?_ga=2.7872757.650815948.1619438069-919169911.1611597417 (accessed on 26 April 2021).

22. Bocken, N.; Strupeit, L.; Whalen, K.; Nußholz, J. A review and evaluation of circular business model innovation tools. Sustainability 2019, 11, 2210. [CrossRef]

23. IDEO. Ellen MacArthur Foundation. In The Circular Design Guide; 2017. Available online: https: / / www.circulardesignguide.com (accessed on 26 April 2021).

24. Camacho-Otero, J.; Selvefors, A.; Boks, C. Circular design tools: (how) do they understand the consumer? In Proceedings of the 3rd PLATE 2019 conference on Product Lifetimes and the Environment, Berlin, Germany, 18-20 September 2019; TU Berlin University Press: Berlin, Germany, 2019.

25. Wiithaa. Circulab Board, n.d. Available online: https:/ / circulab.eu/tools (accessed on 28 February 2019).

26. Evans, J.; Bocken, N.M.P. The Circular Economy Toolkit. 2013. Available online: http:/ / circulareconomytoolkit.org/about.html (accessed on 28 February 2019).

27. Sinclair, M.; Sheldrick, L.; Moreno, M.; Dewberry, E. Consumer intervention mapping-A tool for designing future product strategies within circular product service systems. Sustainability 2018, 10, 2088. [CrossRef]

28. Van Dam, S.S.; Bakker, C.A.; De Pauw, I.; Van Der Grinten, B. The circular pathfinder: Development and evaluation of a practice-based tool for selecting circular design strategies. In Proceedings of the 2nd PLATE 2017 conference on Product Lifetimes and the Environment, Delft, The Netherlands, 8-10 November 2017; IOS Press BV: Delft, The Netherlands, 2017. [CrossRef]

29. Selvefors, A.; Rexfelt, O.; Strömberg, H.; Renström, S. Re-framing Product Circularity from a User Perspective. In Proceedings of the DRS 2018 Conference, Design Research Society, Limerick, Ireland, 25-28 June 2018; Design Research Society: London, UK, 2018. 
30. Abras, C.; Maloney-Krichmar, D.; Preece, J. User-Centered Design. Berkshire Encyclopedia of Human-Computer Interaction; Bainbridge, W.S., Ed.; Berkshire: Great Barrington, MA, USA, 2004; Volume 2, pp. 763-768.

31. Selvefors, A.; Rexfelt, O. A tool for charting circular consumption journeys. In Proceedings of the 19th European Roundtable for Sustainable Consumption and Production, Barcelona, Spain, 15-18 October 2019; Universitat Politècnica de Catalunya: Barcelona, Spain, 2019.

32. Pugh, S. Concept selection: A method that works. In Proceedings of the International Conference on Engineering Design, Heurista, Zürich, Switzerland, 9-13 March 1981.

33. George, M.L. Lean Six Sigma for Service: How to Use Lean Speed and Six Sigma Quality to Improve Services and Transactions; McGrawHill Education: New York, NY, USA, 2003. 